\title{
Maternal mortality: a retrospective analysis of 6 years in a tertiary care centre
}

\author{
Monica Parmar, Sushruta Shrivastava*, Anjali Kanhere, Shweta Patel
}

Department of Obstetrics and Gynecology, Chirayu Medical College and Hospital, Bhopal, Madhya Pradesh, India

Received: 07 November 2017

Accepted: 02 December 2017

\section{*Correspondence:}

Dr. Sushruta Shrivastava,

E-mail: vikrantsush18@gmail.com

Copyright: (C) the author(s), publisher and licensee Medip Academy. This is an open-access article distributed under the terms of the Creative Commons Attribution Non-Commercial License, which permits unrestricted non-commercial use, distribution, and reproduction in any medium, provided the original work is properly cited.

\begin{abstract}
Background: Pregnancy, although being considered a physiological state, carries the risk of serious maternal morbidity and at times death. This is due to various complications that may occur during pregnancy, labour or thereafter. Worldwide 3,03,000 women are dying of pregnancy related complication annually.

Methods: The medical records of all maternal death occurred over a period of last five years between August 2011 to August 2017 in the Department of Obstetrics and Gynaecology at our tertiary care hospital were reviewed and analysed.

Results: It is observed that out of total 30 patients, 24 (80\%) deaths were from 20-30 year of age followed by 5 (16.67\%) deaths from above 30 years of age. In the study period, $40 \%$ of maternal deaths were due to direct causes, haemorrhage $(8 / 12 ; 66.67 \%)$ was main direct causes of obstetric death.

Conclusions: The complications leading to maternal death can occur without warning at any time during pregnancy and childbirth. Most maternal deaths are preventable by optimum utilization of existing maternal and child health care facilities. Complications require prompt access to quality obstetric services equipped with life-saving drugs, intensive care unit, and the ability to provide blood transfusions and to perform surgical interventions as per the need.
\end{abstract}

Keywords: Direct and indirect causes of death, High risk pregnancy, Maternal mortality

\section{INTRODUCTION}

Pregnancy, although being considered a physiological state, carries the risk of serious maternal morbidity and at times death. This is due to various complications that may occur during pregnancy, labour or thereafter. According to the World Health Organization (WHO), "A maternal death is defined as death of a woman while pregnant or within 42 days of termination of pregnancy, irrespective of the duration and site of pregnancy, from any cause related to or aggravated by pregnancy or its management but not from accidental or incidental causes" (ICD-10). The number of women and girls who died each year from complications of pregnancy and childbirth declined from 532,000 in 1990 to 303,000 in
2015. From 1990 to 2015 , the global maternal mortality ratio declined by 44 per cent; from 385 deaths to 216 deaths per 100,000 live births, according to UN interagency estimates. These improvements are particularly remarkable in light of rapid population growth in many of the countries where maternal deaths are highest. Still, over 800 women are dying each day from complications in pregnancy and childbirth. ${ }^{1}$

According to data published by sample registration system, India in December 2013, the maternal mortality ratio has reduced from $254 / 100,000$ births in 2004-2006 to $212 / 100,000$ in $2007-2009$ to $178 / 100,000$ in $2010-12$ with the highest maternal mortality ratio (MMR) in Assam (328) and lowest in Kerala (66). ${ }^{2}$ The states of 
Jharkhand/Bihar stand at MMR of 219 which is higher than the national average. The maternal mortality ratio of Madhya Pradesh is $221 / 100,000{ }^{1}$

This present study was conducted to review the causes of maternal death at a tertiary care hospital of central India.

\section{METHODS}

The present study was a retrospective study, conducted in the Department of Obstetrics and Gynecology in our tertiary care Medical College and Hospital. Data regarding maternal mortality was collected from Medical Record section of our hospital. The medical records of all maternal death occurred over a period of last six years between August 2011 to August were reviewed after approval from research committee.

A total of 30 maternal deaths were analysed. In this study of maternal mortality, the details were recorded in the designed proforma.

Every maternal death was scrutinized from various aspects likely to be related to death such as age, locality of residence, parity, gestational age, antenatal care, admission - death interval, condition of the women at admission, cause of death and communication facility and delay if any in reaching the tertiary care teaching hospital from the primary care centre. Results were analysed by using percentage.

\section{RESULTS}

The epidemiological characteristics of maternal deaths of 30 patients are shown in (Table 1). It is observed that 24 (80\%) deaths were from 20- 30 year of age followed by 5 $(16.67 \%)$ deaths above 30 years of age.

$16(56.67 \%)$ maternal deaths were from rural areas as compared to $43.3 \%$ from urban areas.

In the study period, $15(50 \%)$ patients were multigravida and $14(46.67 \%)$ patients were primigravida. Only 1 patient was grand multipara.

$24(79.9 \%)$ patients died in postpartum period, 11 patients were referred to our institute in postpartum period. Out of these $11(45.6 \%)$ were delivered by caesarean section (7 patients underwent LSCS at private hospital), 12 patients were delivered vaginally (6 at our institute, 5 at private hospital and 1 was home delivery), with 1 instrumental delivery (forceps). 1 patient had undergone emergency laparotomy for ruptured uterus. 6 patients were delivered preterm and 18 were delivered at term. Out of these 2 were intrauterine demise, 2 were preterm neonatal deaths and 2 were still born.

Three patients died while they were pregnant, 1 had severe MS with cardiogenic shock referred to our hospital for ventilator support and ICU care, 1 had accidental burn and 1 patient died because of road traffic accident.

Table 1: Sociodemographic characteristics.

\begin{tabular}{|c|c|c|}
\hline Age & $\begin{array}{l}\text { No. of patients } \\
(\mathbf{N}=30)\end{array}$ & Percentage \\
\hline Up to 19 years & 1 & 3.3 \\
\hline $20-30$ years & 24 & 80 \\
\hline$>30$ years & 5 & 16.67 \\
\hline \multicolumn{3}{|l|}{ No. of pregnancies } \\
\hline Primigravida/primipara & 14 & 46.67 \\
\hline Multigravida & 15 & 50 \\
\hline Grand multigravida & 1 & 3.3 \\
\hline \multicolumn{3}{|c|}{ Pregnancy status at the time of death } \\
\hline Antenatal & 03 & 10 \\
\hline Postnatal & 24 & 79.9 \\
\hline Abortion & 03 & 10 \\
\hline \multicolumn{3}{|l|}{ Registered } \\
\hline Booked & 18 & 60 \\
\hline Unbooked & 12 & 40 \\
\hline \multicolumn{3}{|l|}{ Residence } \\
\hline Rural & 17 & 56.67 \\
\hline Urban & 13 & 43.33 \\
\hline Route of delivery & $(\mathrm{N}=\mathbf{2 4})$ & \\
\hline Vaginal & 10 & 41.67 \\
\hline LSCS & 11 & 45.83 \\
\hline Forceps delivery & 1 & 4.1 \\
\hline Breech & 1 & 4.1 \\
\hline $\begin{array}{l}\text { Laparotomy for } \\
\text { ruptured uterus }\end{array}$ & 1 & 4.1 \\
\hline
\end{tabular}

Table 2: Overview of different factors leading to maternal mortality.

\begin{tabular}{|c|c|c|}
\hline Causes of mortality & $\begin{array}{l}\text { Number of } \\
\text { patients } \mathbf{N}=\mathbf{3 0}\end{array}$ & Percent \\
\hline Haemorrhagic shock & 8 & 26.67 \\
\hline Anaemia & 5 & 16.67 \\
\hline Septicaemia & 6 & 20 \\
\hline Medical disorder & 13 & 43.33 \\
\hline Cardiac disease & 3 & 10 \\
\hline DIC & 6 & 20 \\
\hline & 1 & 3.3 \\
\hline Others Medulloblastoma & 1 & 3.3 \\
\hline Burn & 1 & 3.3 \\
\hline
\end{tabular}

*one patient may have multiple factors leading to mortality

The other three patients died after abortion. One had post abortion septicaemia secondary to chicken pox infection and jaundice. One patient presented to us with ruptured uterus at 3 months of gestation with severe anaemia and haemorrhagic shock after taking MTP pills (took on her own). She died within 4 hours of admission. The third patient presented to us with pulmonary embolism and respiratory distress, she was primigravida with 10 weeks of gestation with multiple fibroids (uterus size 36 weeks) with DVT. The patient died because of pulmonary embolism. 
In the study period, $40 \%$ of maternal deaths were due to direct cause (Table 3); haemorrhage $(9 / 12 ; 75 \%$ ) was main direct cause of obstetric death. Out of these 9 patients 3 were delivered vaginally. Two patients were delivered in private hospital had traumatic PPH and referred to our institute after delivery for further management. The third patient was diagnosed to have HELLP syndrome and had atonic PPH because of the adherent placenta after delivery, for which, obstetric hysterectomy was done.

Table 3: Obstetric causes of death (direct cause).

\begin{tabular}{|lll|}
\hline Causes & Cases $(\mathbf{n = 1 2})$ & Percentage \\
\hline Eclampsia & 1 & 8.33 \\
\hline Severe preeclampsia & 1 & 8.33 \\
\hline HELLP & 2 & 16.67 \\
\hline Hemorrhagic shock & 9 & 75 \\
\hline
\end{tabular}

*one patient may have multiple factors leading to mortality

One patient underwent exploratory laparotomy for ruptured uterus as a result of hyper stimulation in labour. The other 5 patients were delivered by caesarean section, 2 of these patients had central placenta praevia, for which sequential devascularisation and obstetric hysterectomy was done. One patient was referred from other institute after obstetric hysterectomy in view of atonic PPH, she died after 3 days because of DIC.

Table 4: Co-morbid medical conditions causing death (indirect cause).

\begin{tabular}{|lll|}
\hline Medical condition & Cases $(n=18)$ & Percentage \\
\hline Hepatitis & 6 & 33.33 \\
\hline Anemia & 5 & 27.78 \\
\hline Heart disease & 3 & 16.67 \\
\hline ARDS & 1 & 5.55 \\
\hline ARF & 6 & 33.33 \\
\hline
\end{tabular}

Table 5: Admission death interval time.

\begin{tabular}{|lll|}
\hline Time (hours) & Cases $(\mathbf{N}=30)$ & Percentage \\
\hline$<4$ & 1 & 3.3 \\
\hline $4-24$ & 6 & 20 \\
\hline $24-48$ & 5 & 16.67 \\
\hline$>48$ & 18 & 60 \\
\hline
\end{tabular}

$21(87.5 \%)$ patients died after 48 hours of delivery and 3 (12.5\%) patients died within 48 hours of delivery (Table $6)$.

Indirect causes/ comorbid medical conditions contributing to the death of the patient are listed in (Table 4). Leading indirect cause was hepatitis $(33.33 \%)$ followed by anaemia (27.8\%), heart disease (16.67\%), $\operatorname{ARF}(33.33 \%)$ and $\operatorname{ARDS}(5.55 \%)$. The main reason behind ARF was haemorrhage and delay in taking the appropriate corrective measures. Two patients had pulmonary thromboembolism.
Maximum patients in the present study died after 48 hours $(60 \%), 40 \%$ patients died within 48 hours of admission to our hospital (Table 5).

Table 6: Delivery death interval.

\begin{tabular}{|lll|}
\hline Time & Cases $(\mathrm{N}=24)$ & Percentage \\
\hline <4 hours & 0 & 0 \\
\hline 4-48 hours & 3 & 12.5 \\
\hline 48 hours - 1 weeks & 9 & 37.5 \\
\hline 1 week - 3 weeks & 9 & 37. \\
\hline 3 weeks - 6 weeks & 3 & 12.5 \\
\hline
\end{tabular}

\section{DISCUSSION}

Death of mother is a tragic event. A vast majority of maternal deaths are preventable. High maternal mortality indicates poor maternal and child health care $(\mathrm{MCH})$. A high rate of the same reflects poor Antenatal care, late referrals, illiteracy and low socio-economic status. Various studies in India in the last 15 years have shown wide variation in MMR ranging from 47/100000 to 625/ 100000 births. $^{2-7}$

In the present study the maximum maternal death was seen in the age group of 20-30 years $(79.9 \%)$ and most of the patients belonged to rural area $(56.67 \%)$. These findings were similar to various studies by Jain, Jadhav, Pal, Onakewhor, Shah and Khandale. ${ }^{4-9}$ Poverty, female illiteracy, negligence towards female health and nutritional status are major contributory social risk factors. Marriage at very young age is an additional contributory factor, one patient was under 19 years of age in our study. As the patients, being illiterate, don't know the benefits of family planning, antenatal care.

Majority patients died in postpartum status (79.9\%). Our institute being a tertiary care centre gets referred patients from the nearby rural areas or nearby private nursing homes leading to delay in referral. According to the study done by Khandale et al there were three types of delay in referring the patient to higher centres leading to higher maternal mortality. ${ }^{9}$

- $\quad$ Type 1 delay - delay in decision making to seek help

- $\quad$ Type 2 delay - delay in transport due to poor roads and unavailability of vehicles

- $\quad$ Type 3 delay - delay at institutional level.

They found the type 1 delay as most common among the maternal death. Most of the patients referred to us also came very late. Late referral to higher centre decreases the chances of recovery. As in our records the reason for delay in referral were not mentioned we could not analyse it. The most common direct cause of maternal death in our study was haemorrhage $(75 \%)$ followed by preeclampsia and its complication like HELLP syndrome. According to the worldwide maternal mortality update by UNICEF, haemorrhage remains the leading cause of maternal mortality, accounting for over one quarter (27 
per cent) of deaths. ${ }^{1}$ In other studies, done by Jain, Jadhav, Pal, Onakewhor, Shah, Murthy and Khandale eclampsia and preeclampsia, haemorrhage were main direct causes of obstetric death. ${ }^{4-9}$

In our institute $18 / 30$ patients had co morbid medical disorders which lead to the maternal mortality. Hepatitis $(33.33 \%)$ was the most common factor followed by anaemia $(27.78 \%)$. The incidence of liver disorders in pregnancy varies in different parts of the world and it may present with subtle changes in liver biochemical profile or with fulminant hepatic failure (FHF). The overall incidence of liver disorder in pregnancy in our institution was $1.96 \%$ as per the study conducted by Sharma et al. ${ }^{10}$ But in the studies by Ashok V, Guin G, Purandare N, Pal SJ, the major indirect cause of death was anaemia with the percentage varying from $15 \%$ to $65 \% .{ }^{11-14}$ Correction of anaemia at grass root level is very important to prevent these deaths. $\mathrm{MCH}$ is essential as regular ANC check-ups can help detect and correct anaemia.

Even today large numbers of maternal deaths are because of haemorrhage, PIH, anaemia. All these are preventable causes of maternal mortality provided the treatment started in time. Unfortunately, in many cases, patients were referred from nearby places very late and in critical condition. Improvements in maternal nutrition; early identification and registration of all pregnant women in the first trimester of pregnancy; identification of high-risk pregnancies promptly and referred in time to a hospital for appropriate interventions and management would be the measures needed to make motherhood safe.

\section{CONCLUSION}

Maternal death is a major setback not only to the family but to a society and to the nation also. High MMR reflects the poor health care facility, low educational status and poverty of the nation. It can be prevented by improving the health care facilities in rural areas by ensuring round the clock availability of certain basic drugs like injection magnesium sulfate, tablet misoprostol as most maternal deaths in rural areas are still due to eclampsia and post-partum haemorrhage.

National Rural Health Mission (NRHM) can play a major role in reducing maternal mortality by advocating institutional deliveries and timely referral of high risk cases. Along with improving the health care facility, there is high need of improving the educational status and facilities for females. Nutritional status of adolescent girls should be improved as they are going to be the future mothers.

There is a need to make pregnant patients and caregivers aware about the warning signs of pregnancy. High risk cases should be identified. Early referral, easy transport, up-gradation of hospitals and health facilities at rural level, monitoring of health services can reduce maternal mortality.

Funding: No funding sources

Conflict of interest: None declared

Ethical approval: The study was approved by the Institutional Ethics Committee

\section{REFERENCES}

1. WHO. Trends in estimates of maternal mortality ratio (MMR; maternal deaths per 100,000 live births) 1990-2015. Source: WHO, UNICEF, UNFPA, World Bank Group and UNPD (MMEIG). 2015. Available at https://data.unicef.org/topic/maternalhealth/maternal-mortality/\#

2. Special Bulletin on Maternal Mortality. Government of India. Available at http://www.censusindia.gov.in/vital_statistics/SRS_ Bulletins/MMR_Bulletin-2010-12.pdf. Accessed 24 Aug 2015.

3. Puri A, Yadav, Jain N. Maternal mortality in an urban care hospital of north India. J Obstet Gynaecol India. 2011;61:280-5

4. Jain M, Maharaje S, Maternal mortality: a retrospective analysis of ten years in matertiary care hospital. Indian J Prev Soc Med. 2003;34:103-11.

5. Jadhav AJ, Rote PG. Maternal mortality-changing trends. J Obstet Gynaecol India. 2007;57:398-400.

6. Pal A, Ray P, Hazra S, Mondal TK. Review of changing trends in maternal mortality in a rural medical college in west Bangal. J Obstet Gynecol India. 2005;55:521-4.

7. Onakewhor JU, Gharoro EP. Changing trends in maternal mortality in a developing country. Niger $\mathbf{J}$ Clin Pract. 2008;11:111-20.

8. Shah RJ, Ali I, Banday A, Faziili A, Khan I. Analysis of maternal mortality in a small teaching hospital attached to tertiary care hospital. Indian $\mathbf{J}$ Community Med. 2008;33:260-2.

9. Khandale SN, Kedar K. Analysis of maternal mortality: a retrospective study at tertiary care centre. Int J Reprod Contracept Obstet Gynecol 2017;6:1610-3.

10. Sharma S, Aherwar R, Jawade S. Maternal and fetal outcome in jaundice complicating pregnancy: a prospective study. Int J Reprod Contracept Obstet Gynecol. 2016;5:1084-7.

11. Ashok V, Santosh M, Anupa S. A study on maternal mortality. J Obstet Gynecol India. 2008;58:227-9.

12. Guin G, Sahu B, Khare S, Kavishwar A. Trends in maternal mortality and impact of Janani Suraksha Yojana (JSY) on maternal mortality ratio in a tertiary referral hospital. J Obstet Gynaecol India 2012;62:307-11.

13. Purandare N, Chandock AS, Upadhya S, Sanjanwala SM, Saraogi RM. Maternal mortality at a referral centre: A fi ve year study. J Obstet Gynecol India. 2007;57:248-50. 
14. Pal SJ, Rao MA. A three-year review of maternal mortality in a district hospital on the west coast in south India (April 2011-2014). Int J Innov Res Dev. 2014;3:15-21.
Cite this article as: Parmar M, Shrivastava S, Kanhere A, Patel S. Maternal mortality: a retrospective analysis of 6 years in a tertiary care centre. Int J Reprod Contracept Obstet Gynecol 2018;7:224-8. 